\title{
Spontaneous Hemothorax Secondary to Oral Anticoagulation Therapy
}

\author{
Oral Antikoagülan Tedaviye Sekonder Spontan Hemotoraks
}

\author{
Akkan Avci', Mürsel Koçer ${ }^{1}$, Müge Gülen ${ }^{4}$, Mehmet Oğuzhan Ay ${ }^{1}$, Ferhat İçme ${ }^{3}$, Begüm Şeyda Avci \\ 'Department of Emergency Medicine, Adana Numune Research and Training Hospital, Adana, Turkey \\ 2Department of Internal Medicine, Adana Numune Research and Training Hospital, Adana, Turkey \\ ${ }^{3}$ Department of Emergency Medicine, Ataturk Research and Training Hospital, Ankara, Turkey \\ ${ }^{4} \mathrm{Clinic}$ of Emergency Medicine, Yunus Emre State Hospital, Eskişehir, Turkey
}

\section{ABSTRACT}

Introduction: Occurrence of spontaneous hemothorax associated with the usage of oral anticoagulant is a rare complication.

Case Report: In this paper, a case of an 84-year-old man who was admitted to the emergency department with dyspnea and in whom we detected spontaneous hemothorax due to warfarin was reported.

Conclusion: Patients receiving oral anticoagulant treatment should be closely monitored for effective anticoagulation and adverse effects, and if dyspnea occurs, hemothorax should be considered in the differential diagnosis.

Keywords: Warfarin, hemothorax, INR

Received: 04.12.2013 Accepted: 27.01.2014

\section{ÖZET}

Giriş: Oral antikoagülan kullanımına bağlı spontan hemotoraks görülmesi nadir bir komplikasyondur.

Olgu Sunumu: Bu yazıda, acil servisimize nefes darlığı şikayeti ile başvuran ve warfarin kullanımına bağlı spontan hemotoraks saptanan 84 yaşındaki bir hastayı sunduk.

Sonuç: Oral antikoagülan tedavi alan hastaların, etkin antikoagülan tedavinin sağlanabilmesi ve yan etkiler bakımından yakından takip edilmeleri ve bu hastalarda nefes darlığı gelişmesi halinde hemotoraksın ayırıcı tanıda akılda tutulması gerektiğini vurgulamayı amaçladık.

Anahtar Kelimeler: Warfarin, hemotoraks, INR

Geliş Tarihi: 04.12.2013 Kabul Tarihi: 27.01.2014

\section{Giriş}

Oral antikoagulan olarak kullanılan warfarin türevleri K vitamin antagonistidir. Warfarin, primer ve sekonder venöz tromboemboli profilaksisinde, prostetik kalp kapağı veya atriyal fibrilasyonu olanlarda sistemik embolinin önlenmesinde, periferik arter hastalığında, miyokard infarktüsü sonrası sistemik embolinin önlenmesinde ve rekürren miyokard infarktüsü riskini azaltmada etkilidir. Oral antikoagülanların en sık görülen yan etkileri, aşırı dozda verildiklerinde spontan kanamalara yol açmalarıdır. Ciltte purpura ve ekimoz şeklinde kanamalar, böbrek, gastrointestinal traktus ve diğer yerlerde kanama yapabilirler (1). En önemli komplikasyonu kanama olmasına rağmen warfarine bağlı hemotoraks gelişimi oldukça nadirdir.

Bu yazıda, warfarin tedavisinin komplikasyonu olarak gelişen bir spontan hemotoraks olgusunu sunduk. Oral antikoagülan tedavi alan hastaların, etkin antikoagülan tedavinin sağlanabilmesi ve yan etkiler bakımından yakından takip edilmeleri ve bu hastalarda nefes darlığı gelişmesi halinde hemotoraksın ayırıcı tanıda akılda tutulması gerektiğini vurgulamayı amaçladık.

\section{Olgu Sunumu}

84 yaşında erkek hasta, 5-6 gün önce başlayan nefes darlığı şikayetiyle acil servise başvurdu. Öyküsünden 4 yıl önce geçirilmiş koroner bypass operasyonu olan hastaya atrial fibrilasyon nedeniyle warfarin tedavisi başlandığı öğrenildi. Travma öyküsü 
bulunmayan hastanın genel durumu iyi, bilinci açıktı. Fizik bakıda, arteriyel kan basıncı 100/60 mmHg, nabız 72/dakika ve aritmikti. Sol hemitoraks'ta skapula altında solunum seslerinde azalma, vibrasyon torasikte azalma, perküsyonda matite varlığı saptandı. Hastanın protrombin zamanı: 17,8 saniye (Normal aralık: 10,9-15,5 saniye) ve international normalized ratio (INR) değeri: 1,415 (Normal aralık: $0,8-1,2)$ olarak bulundu. Toraks tomografisi'nde, sol alt zonda plevral efüzyon ile uyumlu opasite ve düzensiz sınırlı plevral plaklar izlendi (Şekil 1). Hastaya tanısal torasentez yapıldı. Yaklaşık 20 cc defibrine hemorajik sıvı aspire edildi. Warfarin tedavisi kesilen hastaya $5 \mathrm{mg}$ intravenöz K vitamini verilerek takip ve tedavi amaçlı göğüs cerrahisi servisine yatırıldı.

\section{Tartışma}

Warfarin venöz tromboz, pulmoner emboli, atriyal fibrilasyon ve/veya kalp kapak replasmanı ile ilişkili tromboembolik komplikasyonların önlenmesi ve tedavisinde dünya genelinde sık kullanılan bir ajandır. Ancak kanama riskini artırmaktadır (1). Oral antikoagülan tedavinin en önemli komplikasyonu olan kanama, majör ve minör kanama olarak sınıflandırılabilir. Intrakraniyal hemoraji gibi kanamalar ölüm veya hospitalizasyon gerektiren majör kanama olarak tanımlanır. Majör kanama riski, uzun süreli oral antikoagülan tedavi alan hastalarda her yıl için \%1,2 ile \%8,1 olarak bildirilmektedir (2). Kanama riskini etkileyen en önemli faktör antikoagülan tedavi yoğunluğu olup, INR düzeyi major belirleyicidir. Palareti ve arkadaşlarının yaptıkları çalışmada, INR düzeyi 2-2,9'dan 3,0-4,4 aralığına çıktığında kanama komplikasyonunun iki kat, 4,5-6,0 aralığına çıktığında ise dört kat arttığı saptanmıştır. INR düzeyi arttıkça kanama riski artmasına rağmen, kanama epizotlarının \%50'si INR düzeyi 4)ün altındayken görülmektedir (3).

Kanama riskini arttıran hasta ile ilgili faktörler; önceden kanama öyküsü (özellikle gastrointestinal sistem kanaması), inme öyküsü, böbrek yetmezliği, anemi veya hipertansiyon gibi ciddi komorbid durumlar ve kanser varlığıdır. Tedavinin erken dönemlerinde kanama riski daha fazladır (4).

Oral antikoagülan tedaviye bağlı majör kanama sıklıkla gastrointestinal sistem, yumuşak doku ve üriner sistem kaynaklı olup toraksa ait kanamalar nadir görülürler ve tüm kanamaların \% 3'ünü oluşturur (5). Hemotoraks ise oldukça nadir olup literatürde çok az sayıda olgu sunumu şeklinde bildirilmiştir. Yakın zamanda bildirilen bir vakada, aort ve mitral kapak replasmanı sonrası warfarin kullanan bir hastada INR düzeyi 12,9 iken gelişen bir massif spontan hemotorakstan bahsedilmektedir (6). Ancak bu olgulardan farklı şekilde bizim olgumuzdaki hastanın INR düzeyi düşüktü $(1,415)$

Hemotoraksın klinik önemi, intraplevral boşluğa olan kanamanın miktarına, hızına, etyolojisine, eşlikeden pnömotoraks gibi lezyonların varlığına ve kronik hale gelip gelmemesine göre değişiklik gösterir. Hemotoraks, çoğunlukla göğüs duvarı veya intratorasik organların travma ile yaralanması sonucu meydana gelmekle birlikte travmaya bağlı olmaksızın da görülebilir ve nontravmatik ya da spontan

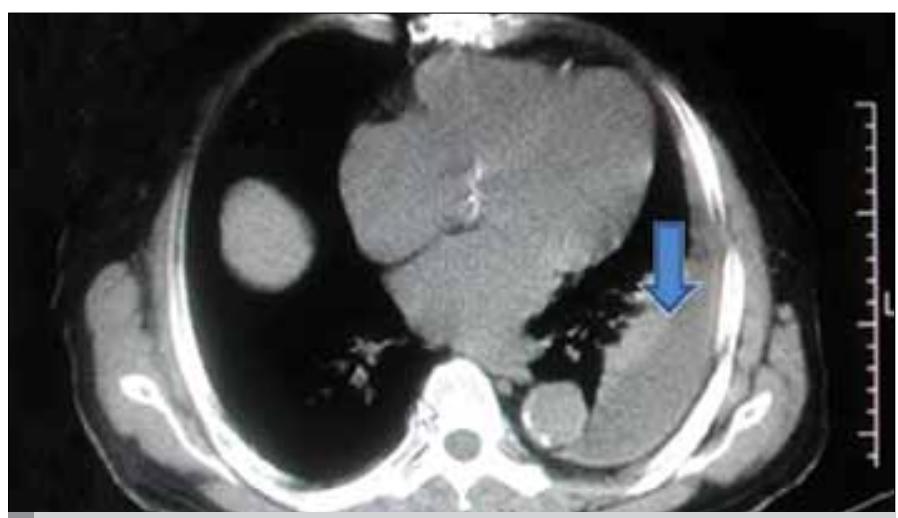

Şekil 1. Hastaya ait bilgisayarlı toraks tomografisinde hemotoraks görüntüsü izlenmektedir

hemotoraks olarak adlandırılır. Bu durumun diğer nedenleri ise, pulmoner emboli, katamenial hemotoraks, hemofili-trombositopeni gibi kan hastalıkları, spontan pnömotoraks, rüptüre torasik aorta, pankreatik psödokist, rüptüre patent duktus arteriyozis, aort koarktasyon rüptürü, herediter hemorajik telenjiektazi, intratorasik ekstramedüller hematopoezis ve sunulan olguda olduğu gibi antikoagülan tedavi komplikasyonudur (7).

Oral antikoagülan kullanan ve minör kanama komplikasyonu ile başvuran hastalara 2-5 mg K vitamini oral, subkutan, intravenöz verilmesi, 6-12 saat arayla INR takibi yapılması ve gerektiğinde kan ürünü transfüzyonu yapılması önerilirken, majör kanama ile gelen hastalara 2-4 ünite taze donmuş plazma (TDP) veya TDP ile birlikte 2-5 mg vitamin $\mathrm{K}$ subkutan veya intravenöz tedavisi verilmesi önerilmektedir (4).

Hemotorakslı olgularda uygulanan temel tedavi, kanlı sıvıyı boşaltmak ve devam eden kanamanın yoğunluğunu belirlemek amacıyla göğüs tüpü takılarak drenaj uygulanmasıdır. Bizim olgumuzda hemotoraks miktarının az olması nedeniyle göğüs tüpü veya torasentez ile sıvı boşaltılmadı. Warfarin tedavisi kesilerek uluslararası kılavuza göre K vitamini tedavisi uygulandı (8).

Son yıllarda pulmoner emboli ve atriyal fibrilasyonlu hastalarda tromboemboli tedavisinde dabigatran, rivaroksaban ve apiksaban gibi yeni oral antikoagülan ajanların vitamin $\mathrm{K}$ antagonisti yerine kullanımı gündemdedir. Bu ajanlardan dabigatran ve rivaroksaban pulmoner emboli tedavisinde, dabigatran ise atriyal fibrilasyonlu hastaların tedavisinde Food and Drug Administration (FDA) onayı almıştır. Vitamin $\mathrm{K}$ antagonisti olan warfarinden farklı olarak, bu yeni ilaçların öngörülebilir ve sabit antikoagülan etkileri vardır ve laboratuvar izlemi gerektirmezler. Oral alım sonrası doruk plazma konsantrasyonlarına dabigatran 1,25-1,5 saat ve rivaroksaban 2,5-4 saat içinde ulaşırlar. Dabigatran'ın yarılanma ömrü 12-17 saat, rivaroksaban'ın ise 7-11 saattir. Bu ilaçların etkilerinin hızlı ve yarılanma ömürlerinin kısa olması, heparinle köprülenme yapmadan kullanılmalarına olanak sağlayabilecektir. Ancak son birkaç yılda kullanıma giren bu yeni ve güçlü antikoagülanların antidotlarının bulunmadığı da unutulmamalıdır $(9,10)$. 


\section{Sonuç}

Oral antikoagülan tedavi alan hastalar olası yan etkiler bakımından yakından takip edilmeli, bu hastalarda nefes darlığı gelişmesi halinde INR değeri düşük olsa dahi warfarine bağlı hemotoraks gelişimi dışlanmalıdır.

Informed Consent: Written informed consent was obtained from the patient who participated in this study.

Peer-review: Externally peer-reviewed.

Author contributions: Concept - A.A., M.Ç.; Design - A.A., M.Ç., M.G.; Supervision - M.O.A.; Materials - A.A., M.Ç., M.G.; Data Collection and/ or Processing - F.I., B.Ş.A.; Analysis and/or Interpretation - F.I., B.Ş.A.; Literature Review - A.A., M.Ç., M.O.A.;Writer - A.A., M.Ç., M.O.A.; Critical Review - B.Ş.A.

Conflict of Interest: The authors declared no conflict of interest.

Financial Disclosure: The authors declared that this study has received no financial support.

Hasta Onamı: Bu çalışmaya katılan hastadan yazılı hasta onamı alınmıştır.

Hakem değerlendirmesi: Dış bağımsız.

Yazar Katkıları: Fikir - A.A., M.Ç.; Tasarım - A.A., M.Ç., M.G.; Denetleme M.O.A.; Malzemeler - A.A., M.Ç., M.G.; Veri toplanması ve/veya işlemesi - F.I., B.Ş.A.; Analiz ve/veya yorum - F.I., B.Ş.A.; Literatür taraması - A.A., M.Ç., M.O.A.; Yazıyı yazan - A.A., M.Ç., M.O.A.; Eleştirel İnceleme - B.Ş.A.
Çıkar Çatışması: Yazarlar herhangi bir çıkar çatışması bildirmemişlerdir.

Finansal Destek: Yazarlar bu çalışma için finansal destek almadıklarını beyan etmişlerdir.

\section{Kaynaklar}

1. Budnitz DS, Pollock DA, Mendelsohn AB, Weidenbach KN, McDonald AK, Annest JL. Emergency department visits for outpatient adverse drug events: demonstration for a national surveillance system. Ann Emerg Med 2005; 45: 197-206. [CrossRef]

2. Levine MN, Raskob G, Landefeld S, Kearon C. Hemorrhagic complications of anticoagulant treatment. Chest 1998; 114: 511-23. [CrossRef]

3. Palareti G, Leali N, Coccheri S, Poggi M, Manotti C, D'Angelo A, et al. Bleeding complications of oral anticoagulant treatment: an inception-cohort, prospective collaborative study (ISCOAT), Italian Study on Complications of Oral Anticoagulant Therapy. Lancet 1996; 348: 423-8. [CrossRef]

4. Ansell J, Hirsh J, Dalen J, Bussey H, Anderson D, Poller L, et al. Managing oral anticoagulant therapy. Chest 2001; 119: 22-38. [CrossRef]

5. Landefeld CS, Beyth RJ. Anticoagulant-releated bleeding; clinical epidemiology, prediction and prevention. Am J Med 1993; 95: 315-28. [CrossRef]

6. Doğan NÖ, Günaydın GP, Tekin M, Çevik Y. Nontraumatic massive spontaneous hemothorax with concomitant warfarin use. Case Rep Emerg Med 2013; article ID: 546024.

7. Hylek EM. Complications of oral anticoagulant therapy: bleeding and nonbleeding, rates and risk factors. Seminars in Vascular Medicine 2003; 3: 271-8. [CrossRef]

8. Akay $\mathrm{H}$. The diagnostic and therapeutic approach in hemothorax. Solunum 2002; 4: 195-205.

9. Stangier J, Rathgen K, Stähle H, Gansser D, RothW. The pharmacokinetics, pharmacodynamics and tolerability of dabigatran etexilate, a new oral direct thrombin inhibitor, in healthy male subjects. Br J Clin Pharmacol 2007; 64: 292-303. [CrossRef]

10. Mismetti P, Laporte S. Rivaroxaban: clinical pharmacology. Ann Fr Anesth Reanim 2008; 27: 16-21. [CrossRef] 